\title{
PELATIHAN MODEL PENDIDIKAN KARAKTER ANAK PADA IBU RUMAH TANGGA MELALUI BADAN KONTAK MAJLIS TA'LIM
}

\author{
Siti Rosada, Dita Hildayatni, Faizatul Muslimah, Hanif Aruni. \\ sitirosada12@gmail.com \\ Mahasiswa Fakultas Agama Islam
}

\begin{abstract}
ABSTRAK
Majelis Ta'lim “Nurul Hikmah" yang terletak di Kp Jati Parung Rt: 01/Rw: 05 No 8A Kec. Parung Kab. Bogor ini, memiliki rutinitas kegiatan yang berbeda Adapun program kegiatan yang biasa dilaksanakan oleh majelis ta'lim ini adalah program kegiatan di bidang dakwah, pendidikan, kerjasama, sosial, ekonomi, dan kesehatan. Dr. KH. Ahmad Mukri Aji, MA., MH ( ketua BKMT kecamatan Parung sekaligus ketua MUI kabupaten Bogor) menyatakan bahwa materi yang diberikan pada kegiatan majelis ta'lim tersebut cukup bervariasi, namun materi tentang model pendidikan karakter anak pada ibu rumah tangga belum pernah disajikan secara khusus dan terstruktur. Karena melalui materi tersebut, ibuibu yang notabenenya adalah sebagai panutan utama bagi anak dalam keluarga, mampu mendidik dan mengembangkan anak agar memiliki kepribadian yang berkarakter. Selanjutnya, ibu Hj. Nurhayati (Bupati Bogor) dalam sambutannya lewat majelis ta'lim keliling menuturkan bahwa majelis ta'lim dijadikan sasaran program, kaum perempuan yang telah menjadi ibu memiliki peran penting dalam pembentukan karakter generasi penerus bangsa karena ibu merupakan sumber utama media transformasi nilai-nilai dalam keluarga, baik nilai agama, moral, dan etika maupun pengetahuan dasar kehidupan pada umumnya.
\end{abstract}

Kata Kunci: Ibu Panutan Utama Bagi Anak, Majelis Ta'lim, Pendidikan Karakter Anak.

\section{PENDAHULUAN}

Badan Kontak Majelis Ta'lim (BKMT) merupakan sebuah wadah atau organisasi yang berfungsi untuk mempermudah para jama'ah dalam memperluas wawasan dan meningkatkan keterampilan. Jama'ah yang hadir dalam majelis ta'lim ini, biasanya didominasi oleh ibu-ibu. Adapun program kegiatan yang biasa dilaksanakan oleh majelis ta'lim ini adalah program kegiatan di bidang dakwah, pendidikan, kerjasama, sosial, ekonomi, dan kesehatan.
Badan Kontak Majelis Ta'lim (BKMT) berdiri tanggal 1 Januari 1981 di Jakarta. Organisasi ini lahir dari kesepakatan lebih dari 735 Majelis Ta'lim yang ada di wilayah Jakarta dan sekitarnya. Organisasi BKMT telah berkembang di seluruh wilayah Indonesia. Cakupan perkembangan anggotanya mencapai ribuan majelis ta'lim dengan meliputi jutaan orang jamaah yang tersebar di 34 provinsi. (Sejarah BKMT, http://bkmt.or.id/index/sejarah-bkmt) Program-program BKMT diarahkan pada peningkatan kemampuan ustadzah/ 
mubalighot dalam meningkatkan kualitas majelis ta'lim. Secara umum program BKMT meliputi bidang dakwah, pendidikan, kerja sama, sosial, ekonomi, dan kesehatan.

Majelis ta'lim bersifat terbuka terhadap segala usia, lapisan atau strata sosial, dan jenis kelamin. Waktu penyelenggaraanya pun tidak terikat bisa pagi, siang, sore ataupun malam hari. Majelis ta'lim memiliki dua fungsi sekaligus yaitu sebagai lembaga da'wah dan lembaga pendidikan nonformal. Majelis ta'lim juga merupakan wahana interaksi dan komunikasi yang kuat antara sesama anggota jemaah majelis ta'lim tanpa dibatasi tempat dan waktu. Maka, dalam pergeseran perkembangan zaman yang semakin canggih dan modern, mendidik anak tanpa ilmu mungkin menjadi salah satu kelemahan dalam mendidik.

Peserta yang menjadi sasaran strategi ini adalah ibu-ibu anggota majelis ta'lim Nurul Hikmah di kecamatan Parung berjumlah 50 orang. Sama halnya seperti majelis ta'lim pada umumnya, majelis ta'lim Nurul Hikmah diisi dengan program pengajian yang biasa dilakukan pada majelis ta'lim lainnya. Pengajian tersebut diisi dengan materi-materi yang sudah umum diberikan kepada masyarakat. Berdasarkan hasil wawancara dengan ketua majelis ta'lim dan pengajar majelis ta'lim (ustadzah) serta ibu-ibu anggota majelis ta'lim, menunjukkan bahwa seluruh ibu-ibu majelis ta'lim belum pernah mendapatkan materi tentang pelatihan model pendidikan karakter anak pada ibu rumah tangga melalui BKMT. Ibu-ibu anggota majelis ta'lim ini mendukung adanya pelatihan pendidikan karakter di lingkungan mereka. Selama ini ibu-ibu anggota majelis ta'lim melakukan pendidikan karakter berdasarkan pengalaman pribadi (yang pernah dialami) dan meniru dari yang telah dilakukan oleh orang lain. Oleh karena itu pelatihan model pendidikan karakter ini dilakukan agar ibu-ibu majlis ta'lim Nurul Hikmah mengetahui bagaimana cara membentuk karakter seorang anak menjadi lebih baik dan beretika dalam kehidupan sehari-hari.

\section{METODE PENGABDIAN}

\section{Khalayak Sasaran Strategis}

Peserta yang menjadi sasaran strategis ini adalah ibu rumah tangga yang menjadi anggota Majelis Ta'lim Nurul Hikmah di kecamatan Parung berjumlah 50 orang. Berdasarkan hasil wawancara dengan ketua majelis ta'lim dan pengajar majelis ta'lim (ustadzah) serta ibu rumah tangga yang menjadi anggota majelis ta'lim belum pernah mendapatkan materi tentang Pendidikan Karakter Anak Pada Ibu Rumah Tangga. Ibu rumah tangga yang menjadi anggota majelis ta'lim melakukan pendidikan karakter anak berdasarkan yang telah dilakukan oleh orang tua atau meniru yang dilakukan oleh orang-orang yang ada di sekitar. Dengan kata lain, ibu-ibu melakukan pendidikan karakter anak adalah berdasarkan pengalaman pribadi (yang pernah dialami) dan meniru dari yang telah dilakukan orang lain.

\section{Metode Pelaksanaan Kegiatan}

Metode yang digunakan dalam kegiatan pengabdian pada masyarakat ini adalah pelatihan kepada ibu rumah tangga yang menjadi anggota majelis ta'lim yang berada di kecamatan Parung. Para ibu tersebut mendapat pelatihan 
tentang pendidikan karakter anak. Pelatihan diberikan setelah kegiatan rutin yang dilakukan dalam pengajian mingguan. Langkah-langkah kegiatan pelatihan yang ditempuh adalah sebagai berikut: a. Melaksanakan kegiatan rutin dilakukan dalam pengajian mingguan, seperti membaca shalawat, membaca Qur'an membaca "pujian" dan "hadiah".

b. Menyajikan materi pelatihan berdasarkan manual pelatihan.

\section{Kerangka Pemecahan Masalah}

Langkah-langkah yang dilakukan mulai dari identifikasi masalah sampai dengan dilaksanakannya kegiatan pelatihan ini digambarkan pada bagan dibawah ini:

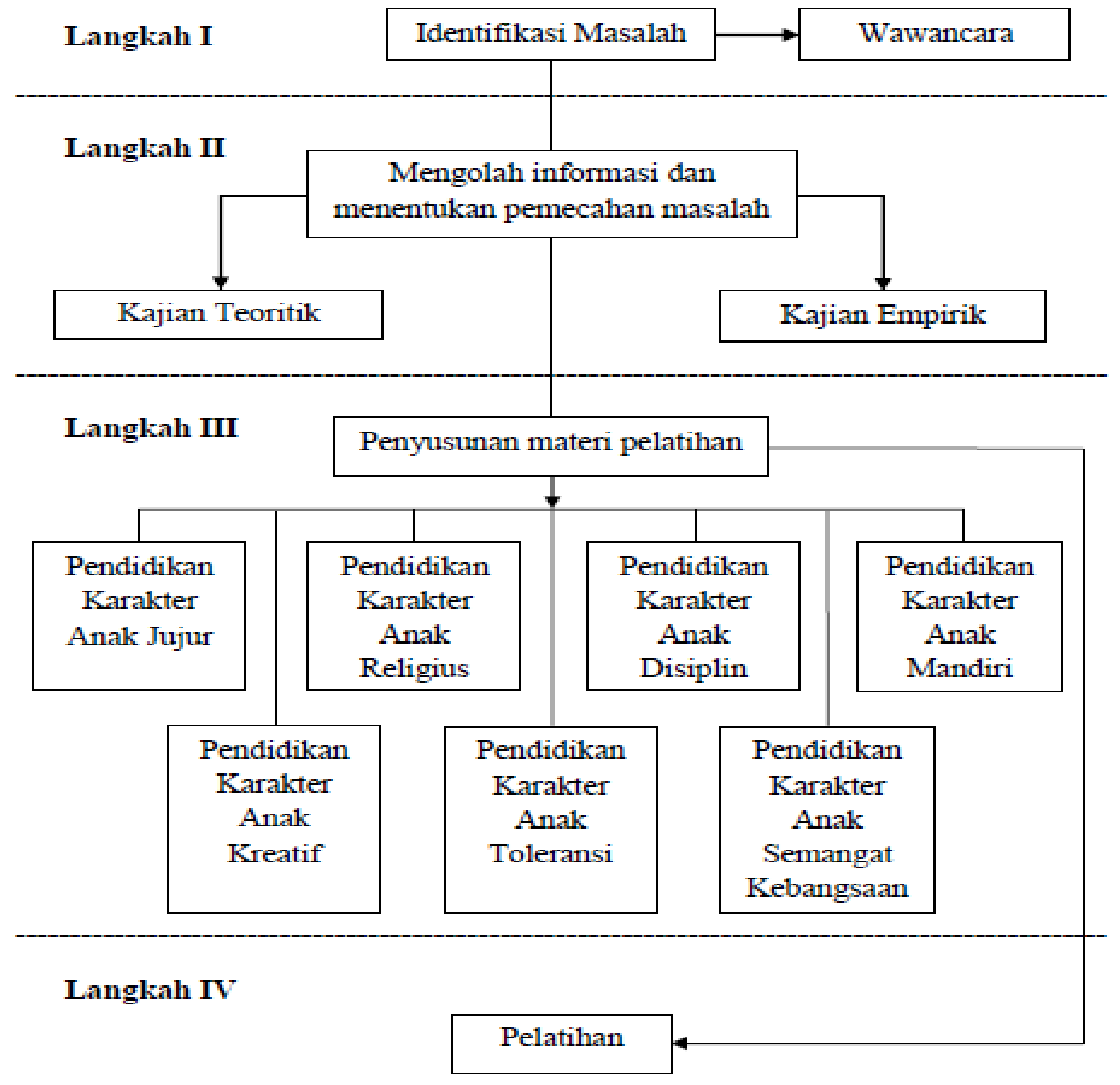

Langkah I, melakukan identifikasi masalah melalui wawancara pada ibu-ibu majelis ta'lim tentang pendidikan karakter anak yang selama ini dilakukan dan materi-materi yang telah diberikan dalam pengajian majelis ta'lim. Hasil wawancara menunjukan bahwa ibu-ibu belum pernah secara khusus 
mendapatkan materi pendidikan karakter anak, sehingga materi pendidikan karakter anak perlu diberikan untuk meningkatkan pengetahuan ibu rumah tangga sehingga dapat mendidik karakter anak dengan baik sesuai dengan ilmu pengetahuan maupun tuntunan agama. Disamping itu, identifikasi masalah juga dilakukan melalui wawancara informal dengan ketua majelis ta'lim dalam suatu pertemuan sebelum pelatihan dan saat pelatihan. Temuan menunjukan bahwa para ibu anggota majelis ta'lim belum mendapatkan pelatihan secara terstruktur dan sistematis tentang pendidikan karakter anak.

Langkah II, tim pelaksana mengolah semua informasi dari hasil wawancara. Kajian teoritik dan empiris dikumpulkan terkait dengan usaha memberikan solusi terhadap masalahmasalah yang telah teridentifikasi. Adapun solusi yang perlu dilakukan adalah melalui pelatihan pendidikan karakter anak untuk meningkatkan pengetahuan pendidikan karakter anak. Pelatihan ini sangat perlu utamanya bagi para ibu rumah tangga yang khususnya mempunyai putra-putri, yang masih dalam jenjang pendidikan sekolah dasar.

Langkah III, menyusun materi pelatihan, yang meliputi pengumpulan referensi terkait dengan pendidikan karakter anak sesuai dengan syariat Islam, contoh-contoh pendidikan karakter anak yang benar dan sesuai dengan tuntunan agama maupun contoh yang menunjukan kekeliruan dalam pendidikan karakter anak, selain itu juga mencari film atau tayangan yang dapat disajikan dalam kegiatan pelatihan yang dapat menunjukan pelaksanaan kegiatan.

Langkah IV, merupakan puncak atau inti kegiatan ini dan tahap yang paling penting. Pada tahap ini, tim pelaksana merealisasikan kegiatan di tempat yang ditentukan untuk melaksanakan pelatihan. Untuk tujuan ini, tim pelaksana berkoordinasi dengan Pembina BKMT kecamatan Parung, serta ketua majelis ta'lim dan penceramah yang sering mengisi kegiatan majelis ta'lim tersebut agar pelaksanaan kegiatan dapat berjalan dengan lancar serta sosialisasi materi pelatihan dan pelaksanaan pelatihan. Langkah dari pelaksanaan pelatihan meliputi menyampaikan tujuan tentang materi pelatihan, permodelan melalui pemberian contoh-contoh kasus, penyampaian materi yang dilakukan dengan ceramah, tanya jawab, dan diskusi. Selanjutnya, peserta bekerja kelompok dalam memecahkan masalah. Langkah-langkah terakhir dari kegiatan adalah memutarkan film dan narasumber menyimpulkan pokok pembahasan yang telah disajikan.

\section{Keberhasilan program,} pelaksanaan pengabdian pada masyarakat berupa pelatihan model pendidikan karakter anak pada ibu rumah tangga melalui majelis ta'lim dievaluasi dengan pengamatan langsung (observation) dan menggunakan tes. Adapun indikator keberhasilan dari kegiatan ini adalah peningkatan pengetahuan tentang pendidikan karakter anak serta kesadaran dalam memberikan pendidikan karakter anak. 


\section{REALISASI PROGRAM}

\section{Anggaran Biaya}

\begin{tabular}{|c|c|c|}
\hline No & Jenis Pengeluaran & Biaya (Rp) \\
\hline 1 & $\begin{array}{l}\text { Peralatan Penunjang: Sewa LCD, sewa printer, } \\
\text { penggandaan modul, }\end{array}$ & Rp. 1.200 .000 \\
\hline 2 & $\begin{array}{l}\text { Bahan Habis Pakai: ATK, map, kertas A4, } \\
\text { penggandaan materi, penggandaan daftar hadir, } \\
\text { tinta print, penggandaan Pre Tes dan Pos Tes, } \\
\text { internet data }\end{array}$ & Rp. 1.305 .200 \\
\hline 3 & Perjalanan: Pelaksanaan pelatihan, survey lapangan & Rp. 2.000 .000 \\
\hline 4 & $\begin{array}{l}\text { Lain-lain: Cetak sertifikat, fee kebersihan, } \\
\text { penggandaan laporan, plakat, dokumentasi, } \\
\text { seminar hasil PKM, }\end{array}$ & Rp. 1.920 .000 \\
\hline & SUB TOTAL (Rp) & Rp. 6.425 .000 \\
\hline
\end{tabular}

\section{Jadwal Kegiatan}

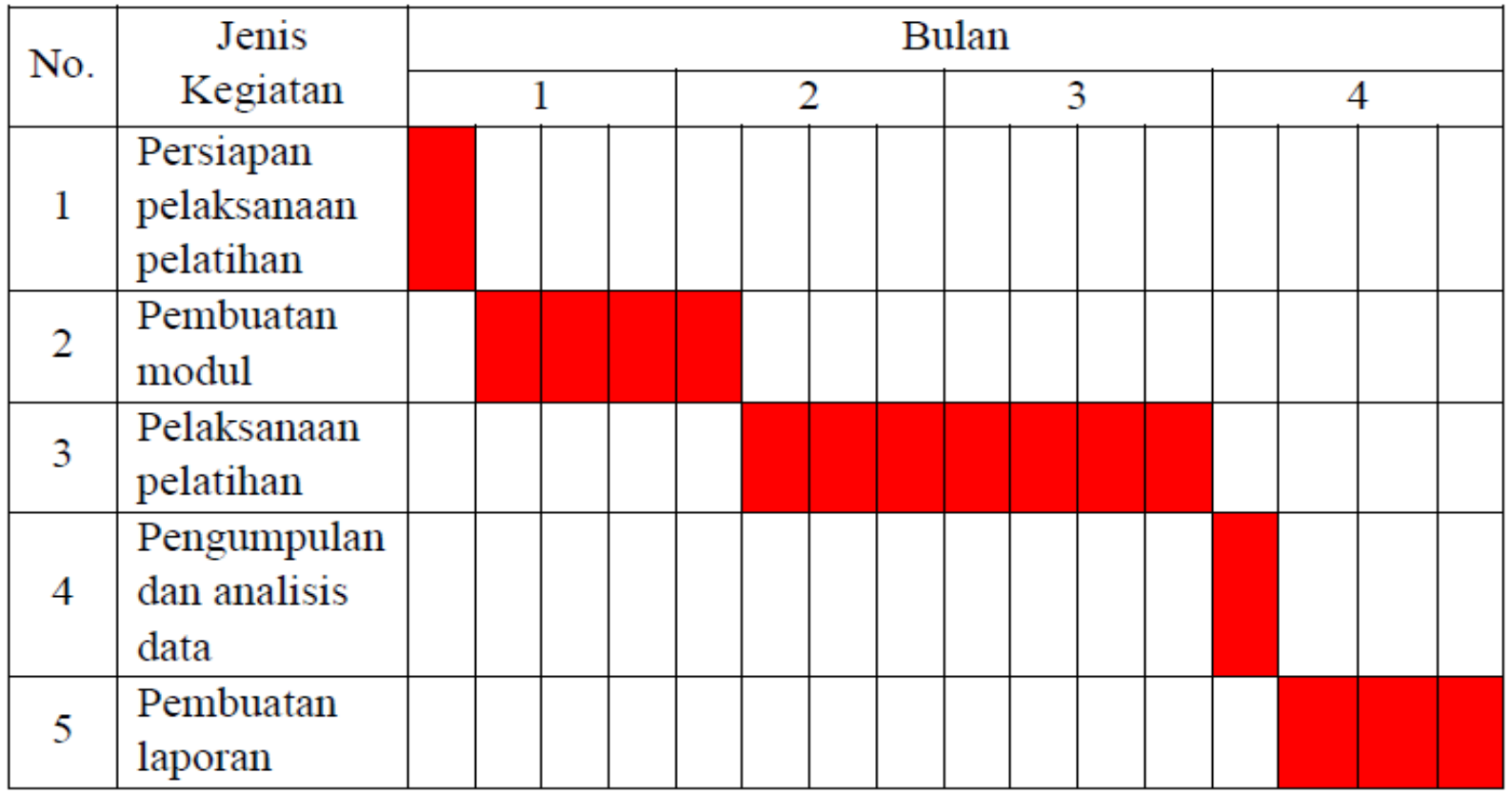




\section{KESIMPULAN}

\section{Luaran}

Luaran dari pengabdian ini yaitu:

a. Diperolehnya model pendidikan karakter anak pada ibu rumah tangga sehingga ibu mampu mendidik dan mengembangkan karakter anakanaknya sebagaimana yang telah dirumuskan dalam manual pelatihan

b. Modul atau manual pelatihan tentang "Model Pendidikan Karakter Anak" 1.3.3 Artikel atau paper pada jurnal nasional.

\section{Manfaat}

Manfaat dari pengabdian ini adalah sebagai berikut:

a. Bagi Pengabdi, Hasil dari pengabdian ini berguna untuk menambah pengetahuan serta

pengalaman sosial mengenai pengabdian kepada masyarakat yang berupa "Pelatihan Model Pendidikan Karakter Anak pada Ibu Rumah Tangga melalui Badan Kontak Majelis Ta'lim".

b. Bagi Ibu Rumah Tangga, Hasil pengabdian ini dapat memberikan wawasan dan keterampilan untuk mengaplikasikan model pendidikan karakter anak dalam pengasuhan di keluarga serta meningkatkan kualiatas mutu ibu-ibu majelis ta'lim.

c. Bagi Anak, Hasil dari pengabdian ini berguna untuk mengembangkan karakter diri anak melalui pendidikan yang diberikan oleh ibu. 